\title{
On the policy space of smart specialization strategies
}

\section{Dominique Foray}

To cite this article: Dominique Foray (2016) On the policy space of smart specialization strategies, European Planning Studies, 24:8, 1428-1437, DOI: 10.1080/09654313.2016.1176126

To link to this article: http://dx.doi.org/10.1080/09654313.2016.1176126

曲 Published online: 31 May 2016.

Submit your article to this journal $๘$

Џll Article views: 108

Q View related articles $\sqsubset$

View Crossmark data $\nearrow$ 


\section{On the policy space of smart specialization strategies}

\section{Dominique Foray}

Economics and Management of Innovation, Institute for Technology and Public Policy, Ecole Polytechnique Fédérale de Lausanne, Lausanne, Switzerland

\begin{abstract}
This paper is about 'smart specialization strategies' as an innovation (or industrial) policy approach. Being a sector non-neutral policy, while promoting a bottom-up principle of entrepreneurial initiative and dynamics, 'smart specialization strategies' occupy a particular place in the innovation policy space. This place is naturally not only filled with 'smart specialization strategies', but also several other approaches in development policy and industrial policy share similar goals and logics. In the paper we will build the innovation policy space, emphasize two important bifurcations within it and explain why various policy approaches are located in the same subspace and what makes them rather similar in terms of governance principles.
\end{abstract}

\section{ARTICLE HISTORY}

Received 25 February 2016

Revised 1 April 2016

Accepted 4 April 2016

\section{KEYWORDS}

Smart specialization; new industrial policy; policy design; entrepreneurial discovery

Research and Innovation Smart Specialization Strategy (RIS3) occupies a particular place in the innovation and industrial policy space. The main 'raison d'être' of RIS3 is to allow government to undertake strategic actions in order to build future competitive advantages, while preserving or even promoting a bottom-up principle of entrepreneurial initiative and dynamics. The main challenge for policies located at this particular place of the policy space is to help governments allocate resources in a non-neutral logic (advantaging thereby some fields or domains), while preventing them to behave as omniscient planners possessing 'ex ante' the full knowledge about future desirable paths of transformation and development of the economy. Of course, this place in the policy space is not only filled with RIS3, but also several approaches in development policy (i.e. Haussmann \& Rodrik, 2003), industrial policy (i.e. Aghion, 2012) or mission-R\&D programmes (i.e. Foray, Mowery, \& Nelson, 2012) share similar goals and logics. All these approaches address the tension between the need for strategic actions undertaken by governments and the need to avoid a central planning mode of resource allocation and to maintain instead a key role for decentralized entrepreneurial choices and initiatives. ${ }^{1}$

In this paper, we will emphasize two important bifurcations in the policy space and will try to explain why some types of policies (including RIS3) are located in the same sub-space and what makes them rather similar, at least in terms of governance principles. 


\section{A first bifurcation: between horizontal policies and sector non-neutral policies (and smart specialization strategies)}

During the last decades, horizontal policies dominated the policy process at the regional level in the European Union (EU). Resources were mostly allocated in a horizontal manner - in order to avoid any preferential interventions and to act on general framework conditions and generic factors (such as public research infrastructure) which are important for the whole system. There were exceptions of course, but horizontal policy (or sectorneutral policy) was the main logic of resource allocation in the framework of regional and cohesion policy. ${ }^{2}$

Horizontal policies are good policies! First, they are likely to improve important components of the regional system of innovation. Second, they minimize risks inherent in any policy which selects projects according to preferred fields (Trajtenberg, 2012). And, indeed, this sort of policy has the potential to stimulate structural changes through various mechanisms such as diversification in firms, spin-offs and start-ups, mobility of people and networking (Boschma \& Frenken, 2011).

\section{The failures of horizontal policies in less advanced regions}

Although this policy was likely to work in the case of top regions, it did not work in the case of transition and less advanced regions (Muscio, Rivera Leon, \& Reid, 2015; Percoco, 2013). Most of the less developed regions and transition regions failed to improve the knowledge gap relative to the top regions. In a few cases, when regions managed to somewhat improve the knowledge gap, they had difficulties to translate it into real economic convergence. This usually happens when improvement in the knowledge gap is mostly a public sector component, with very little effect of the policy in innovation capacities within the private sector (Veugelers \& Mrak, 2009). There is no such thing as a quasi-magical effect of public research improvement, notably in the form of knowledge spillovers.

Why can one observe such a differentiated impact of horizontal policies between regions of different levels of development?

Innovation requires not only general framework conditions - 'the basics have to be right' - but also specific capabilities and resources. In top regions, these capabilities are provided by industrial associations, large companies, universities and public research organizations, through spillovers of research, training and diffusion of technologies to suppliers. These spillovers constitute the complementary capabilities that most Small and Medium Enterprises can draw on even if they have not contributed to their provision (Berger, 2013). However, in the other regions, these sources of complementary capabilities have dried up or have never existed and large holes in the industrial eco-systems have appeared. To take the words of Suzan Berger: 'firms are home alone', she convincingly argues: 'even start ups with great innovation and generous funding cannot do it all in house. They need suppliers, qualified workers and engineers, expertise beyond their own'. In many cases, the ecosystem is too poor to provide all these capabilities.

\section{In less advanced regions policies need to be more specific and complex}

In less advanced and transition regions, regional innovation policy therefore needs to go beyond horizontal measures and address the whole set of capabilities required to innovate 
in 'specific' sectors and emerging fields. This reflects what Hausmann and Rodrik wrote in 2006:

The idea that the government can disengage from specific policies and just focus on general framework conditions in a sector neutral way is an illusion based on the disregard for the specificity and complexity of the requisite publicly provided inputs and capabilities.

In other words, a policy is needed to support not only the development of a public research infrastructure, but also above all the emergence of 'micro-systems of innovation': the network of companies, research institutions, specialized services and complementary capabilities that are mobilized to explore collectively a certain new domain of opportunities. $^{3}$

The following case will help readers to understand the notion of an emerging microsystem of innovation. This case is that of the footwear industry in Northern Portugal, which has undergone profound renewal in a context of frantic global competition. The strategy carried out by the innovation public agency involved the formation of a microsystem of innovation aiming at the development of new forms of flexible automation in the footwear industry. The goal was to achieve the integration of engineering knowledge from the University of Porto, skills of companies specialized in industrial machinery, tools and software, as well as the entrepreneurial vision of a few footwear manufacturing firms which have a good understanding of the urgent need for revival via innovation. The integration of this knowledge facilitated exploration of the potential for automation associated with advanced cutting tools to increase the flexibility and quality of production. Economic experimentation with these technological developments determined a new business model. The latter is based on an increase in the variety of designs and the capacity to rapidly respond to small orders. This development has led one segment of the footwear industry to bypass global competition and become the second most important European producer in terms of exports and value added.

In this example we see the development of a new activity or speciality, complementing the existing structures and assets in order to open and explore new opportunities to transform these structures. Such a process can be described as a smart specialization. What is prioritized here is not a sector (the footwear industry), but a mode of transformation of this sector: a process that does not involve the whole industry but the network of firms, services and research that collaborate to explore a new route for structural change.

This is not a cathedral in the desert here, but knowledge-based activities that are embedded in and complementing existing structures in order to transform them. A smart specialization process, which involves the emergence and growth of a microsystem of innovation, represents, therefore, another mechanism for structural changes perhaps more effective and powerful - in certain types of regional economies. In this case, one can realistically hope for real economic impact since it involves not only supported research, but also the whole micro-system.

The notion of smart specialization, therefore, defines a virtuous process of diversification through the local concentration of resources and capabilities in a certain number of new domains that represent possible paths for the transformation of productive structures. Smart specialization processes reflect the capacity of an economy to generate new activities aiming at transforming the structures. These processes can be spontaneous when firms and other agents have enough capabilities and incentives to open and explore new 
domains of opportunities. In many cases, however, several obstacles and difficulties hinder such spontaneous processes from arising. In such instances, there is a need for a smart specialization 'strategy (or policy)'. This involves putting in place a policy process whereby this sort of new speciality development dynamic can be facilitated. ${ }^{4}$

The example from Northern Portugal also helps to understand that a smart specialization strategy does not necessarily reflect the increase of the relative weight of an industry. It does not aim either at narrowing down the development path of a region or producing some sort of technological monoculture. Smart specialization strategies reflect rather the capacity of an economic system (e.g. a region) to generate new areas of development and new options through the discovery of new domains of opportunity and the local concentration and agglomeration of resources and competences in these domains.

A smart specialization strategy has thus two faces:

- forming capabilities (building micro-systems of innovation)and

- driving structural changes.

Of course in some cases, it could be possible to import all factors of structural changes. One can modernize a tourism sector simply by outsourcing the development and application of Information and Communication Technology (ICT) solutions to companies which are not based in a region, and this can be a good sectoral policy; however, this is not a smart specialization policy. A smart specialization policy addresses not only structural changes, but also the formation of local capabilities to drive these changes.

If the concept of smart specialization is, therefore, associated with the idea that building local capabilities has a value - co-location of firms, research and labour forces in specific domains is a fundamental engine of innovation - this value does not mean that smart specialization is a closed process done for an autarkic region. At any stage in the process, external knowledge and extra-regional resources are required and need to be mobilized.

\section{A problem of choice: towards a second bifurcation in the policy space}

But of course, such a policy has a very different logic than the horizontal policy previously described. We can call it 'non-neutral' (or vertical). It is a very different policy simply because different activities require different things. Supporting biotechnology development for fisheries will require the provision of capabilities in terms of research, suppliers and services which are very different from those required to support the development of advanced manufacturing technologies for the footwear industry or to support the development of ICT for tourism. Such a policy has to deal with the complexity and specificity of each activity and this has a cost. This is 'haute couture' rather than 'ready to wear'. A horizontal policy such as $\mathrm{R} \& \mathrm{D}$ tax credit is 'ready to wear' (it has a cost but is relatively easy to implement). But providing the specific capabilities for a specific emerging activity is 'haute couture' and therefore more costly.

It is, therefore, clear that a local government cannot address all potential specific capabilities and infrastructure needs for all new activities. This implies that choices need to be made between different emerging activities or different opportunities. As said forcefully by Hausmann and Rodrik (2006), it is not that choices are desirable, they are simply inevitable'. 


\section{A second bifurcation: between central modes of planning and self-discovery}

The new policy logic raises thus a problem which is easy to perceive. This is the problem of choosing and selecting a few domains of priorities where the emergence of micro-systems of innovation will be strongly supported and large resources will be concentrated. Indeed, prioritizing certain technologies or domains always entails a risk because it implies predicting the future development of technologies and markets.

There is a long history of policies setting priorities and objectives in a top-down and central planning mode and letting bureaucratic committees decide what was best left to the market. These policies generated a lot of inefficiencies and most often failed to stimulate dynamism and innovation. Such an old-fashioned mode of making choices and establishing priorities was fully used during the golden age of the so-called mission-oriented policies in the post-war period (from the 1960s to the 1990s). Government viewed itself as the omniscient planner with 'ex ante' knowledge about what to do and what to choose in terms of sectors and activities. One could argue that a lot of cluster policies which clearly display some aspects of innovation systems - are very much top-down with governments dictating what technologies should be developed in what places (e.g. the French 'Pôles de Compétitivité'). Given the potential risks of failure (including picking winners, policy capture and anti-competitive effect), the scepticism of many economists about such sector non-neutral policies is fully justified.

However, the essence of a smart specialization strategy does not lie in taking such potential risks of failures and distortions as a good reason for abandoning any policy aiming at supporting the building of capabilities in 'specific' domains. Rather, the approach of smart specialization is to care seriously about the design of the policy process so as to minimize all these risks. To summarize, RIS3 recognizes the need for government to be able to make strategic choices and targeted interventions so as to support the emergence of micro-systems of innovation in specific domains, but it equally recognizes the need to avoid the usual mistakes frequently associated with top-down decisions and central planning mode. Thus, the essential question of a smart specialization strategy is: how can one design a 'specialization' strategy - as presented above - without falling back into a planning mode where government preselects target industries? Dealing with this challenging question, RIS3 places itself within a specific zone of the policy space.

\section{Towards good policy design: entrepreneurial discovery and a few other things}

In the perspective of a non-neutral policy, three types of mistakes need to be considered.

'Mistake type 1' has already been mentioned: the mistake of the omniscient planner who knows what to do and what to choose and does not need any grassroots information. The temptation is high to buy consulting services that will write a nice report using any kind of figures and tables and thereby produce the illusion that the government has 'sufficient information and knowledge' to decide priorities in a top-down manner. Policymakers must guard against the intellectual logic imposed by the principal-agent model, according to which the principal (the government) knows from the start which specializations should be developed and therefore confines itself to setting up incentives for private 
industry to carry out the plan! (Rodrik, 2013). As Sabel said so well: 'What if, as I and many others assume, there are no principals ... with the robust and panoramic knowledge needed for this directive role?' (Sabel, 2004, p. 3). There is a potential mistake here because the logic of RIS3 is that the smart specializations are not given 'ex ante' through some kind of measurement of relative specialization or critical mass and the strategy would simply consist in deepening such relative specialization. In RIS3, the smart specializations need to be discovered among several emerging activities.

'Mistake type 2' - this is the mistake of sectoral prioritization. Sector prioritization generates distortions. There is no point in supporting all firms of a given sector. The point is rather to support new activities and projects at a finer level of granularity.

'Mistake type 3' - this is the mistake of choices made forever (or, this is the mistake of making permanent choices). The profound logic of S3 is about generating new options for further diversification and transformation. This is not about deepening existing specialization.

To minimize the risks of these mistakes which are inherent in any government intervention which selects projects according to preferred fields, the design of the policy process becomes a crucial issue.

\section{Centrality of entrepreneurial discovery}

Reliance on entrepreneurial discovery means that while policy-makers are asking themselves how to develop a unique competitive offer and build capabilities in specific fields, the response is not in building statistical representations of supply and demand, strength and weaknesses, or related variety measures. Mapping science, technology and industries at the regional level is indeed a useful exercise, but cannot be used as the main driver or guidepost for decisions. The fundamental point here is the Hayeckian argument whereby the knowledge about what to do is not obvious. It is knowledge 'of time and place'; this is local knowledge which is dispersed, decentralized and divided. It is hidden and needs to be discovered. The importance of entrepreneurial discovery is, therefore, related to the recognition that the government does not have innate wisdom or 'ex ante' knowledge about future priorities. 'The decisions should rather be informed by the local knowledge, "of time and place", and the entrepreneurial knowledge about opportunities, constraints and challenges.' In other words, the policy process must create opportunities and incentives for economic agents - firms, research centres, independent inventors and lead users who hold information about the technological and market potentials of new domains and new activities to communicate that information to the public agency.

To cap it all, 'entrepreneurial' means a large category of actors in the innovation process, based not only in the region but also elsewhere; and 'discovery' means really discovery and not an 'ex post' qualification of a predetermined set of goals. So the discovery process - discovering which domains of $\mathrm{R} \& \mathrm{D}$ and innovative activities a region should move into to construct its future in the knowledge economy - forms an integral part of political action and must be carried out within the framework of strategic interactions between the government and the private sector.

By opening and exploring new domains of opportunities, the process of entrepreneurial discovery is a central tool to 'solve the information problem that the government alone cannot solve'. As such, it is characterized by a strong learning dimension. 
The social value of a discovery is that it informs the whole system that a particular domain of $\mathrm{R} \& \mathrm{D}$, innovation and structural change is likely to create new opportunities (Hirshleifer, 1971).

Based on this information, the government can use various assessment procedures to select those activities that appear as very promising in terms of future innovations, spillovers and potentials for the transformation of the existing structures and that have scale or agglomeration economies or exhibit the characteristics of coordination failures (Rodrik, 2004). Subsequently, the constitution of scales and critical masses of resources as well as the provision of complementary capabilities will be organized so that a micro-system of innovation can emerge and the policy process will manage the transition from the entrepreneurial discovery phase to the growth of the new activity. The right sequencing in a smart specialization strategy is, therefore, 'from entrepreneurial discovery process to transitory specialisation'.

\section{Entrepreneurial discovery matters twice!}

To understand the great role of entrepreneurial discovery in the design and deployment of a RIS3 and to understand that such an argument is not artificial or feigned or forced, we can conclude that entrepreneurial discovery has two faces:

- First, it is a mechanism to integrate and combine dispersed and fragmented knowledge in order to open and explore a new domain of (market and technological) opportunity. As such it is the initial step in many processes of structural changes.

- Second, it is a mechanism to produce information about the value of the considered domain, in terms of potential innovations, spillovers and structural changes. This information should be used by government when the time comes to choose.

To summarize, the process of entrepreneurial discovery is not just about 'the public sector needing to talk to business firms', as misinterpreted by a few scholars. It involves rather the tangible exploration of a new domain of opportunities: a concrete discovery that will generate relevant information for the government to make adequate choices and selection.

\section{Two other design principles}

Beyond the entrepreneurial discovery process, two other design elements are important in order to minimize the risk of government failures (described above).

Priorities are selected at a finer level of granularity than the sectoral level. This finer level is captured by the notions of 'new activity' or 'emerging micro-system of innovation'.

There is a 'self-destruction mechanism' associated with all priorities, through which support will be discontinued after a certain period of time has elapsed. The right rationale to discontinue support is not about success or failure, but rather that the considered activity is no longer new (Foray, 2015; Rodrik, 2004).

\section{Conclusion}

In this paper we have addressed the policy space of smart specialization strategies (Figure 1). It is a sector non-neutral policy (as opposed to a horizontal and sector-neutral policy), 


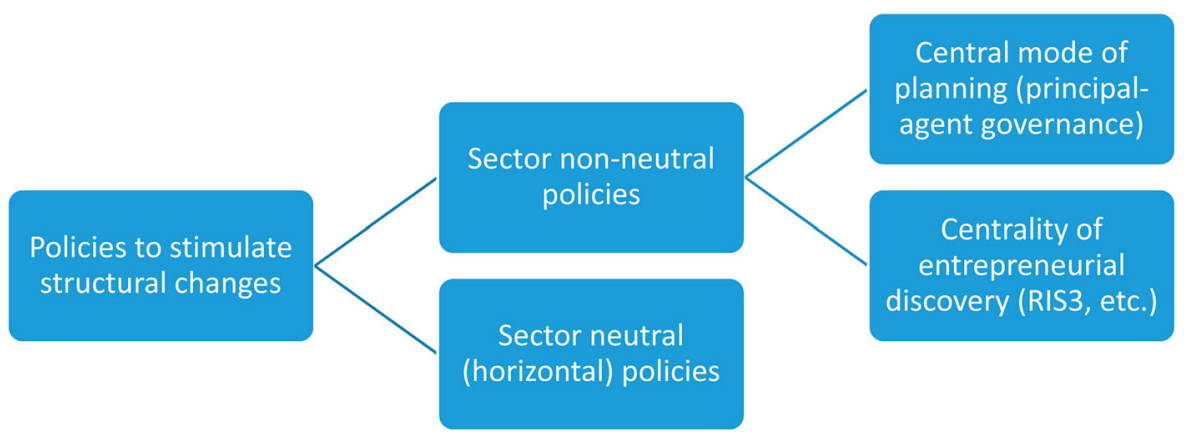

Figure 1. The policy space of smart specialization strategies.

which involves a logic of decentralized discovery process (as opposed to principal-agent governance). This space is not only filled with this approach. With some nuances, various kinds of policy approaches can be located in the same space. This is the case of course for Haussmann and Rodrik's development policy (2003), the pro-competitive sectoral policy of Aghion (2012) (and) some mission-oriented policies (which) address grand challenges. ${ }^{6}$ Perhaps Hirschman's 'Development Project Observed' could be identified as the pioneering study in this strand of policy literature (Hirschman, 1967). ${ }^{7}$

All these approaches try to address the tension between the need for government to take things in hand again by developing a vision, deciding about strategic choices which support some priorities in building future competitive advantages, and the need for decentralized entrepreneurial choices and initiatives. Only a good policy design can help to address such a tension, and the centrality of self-discovery or entrepreneurial discovery is obvious in this policy design. Any 'new' industrial or innovation policy which would not include such a provision would have an entirely different character.

\section{Acknowledgements}

I am grateful to the two anonymous reviewers for their comments and suggestions and I thank Henning Kroll and Roberta Capello for their encouragement and persistence.

\section{Disclosure statement}

No potential conflict of interest was reported by the author.

\section{Notes}

1. A very simple figure placed at the end of the paper supports our argument in both Sections 1 and 2.

2. A sector-neutral (horizontal) policy is a policy that addresses problems that are similar to any company and other innovation actors across sectors and fields. Such policy aims at improving general conditions and fixing generic problems, while minimizing the risks of distortions and government failures.

3. David and Metcalfe (2008) suggest that the term 'innovation system' has been misleading in directing attention to static and durable institutional structures, and argue for greater empirical and policy relevance of their conceptualization of 'micro-systems of innovation' as 
emergent properties of interactions among firms, research, suppliers and so on which develop (often only transiently) for the purposes of solving specific innovation problems. They write: 'In a healthy ERA there would be countless numbers of specialized innovation systems generated at the micro-level; systems that are born and decay as new innovation problems are posed and solved'.

4. Setting up such a process in every European region has become an important objective of EU cohesion policy - known as RIS3 (see Foray, 2015; Foray, David, \& Hall, 2009; McCann, 2015; McCann \& Ortega-Argiles, 2015).

5. As a lesson from the first years of practical implementation in EU regions, it seems that in most cases, regions proceeded the other way: starting with the predetermination of domains and areas of potential specialization (based on different types of statistical representations or problem setting), they then hoped to find entrepreneurial discoveries within these domains (if they are lucky, they will find a few)! See Foray and Frenken (2016) to learn under what conditions such a reverse sequencing is relevant (which is notably the case in regions with poor entrepreneurial capabilities).

6. In 'Choosing races and placing bets' (Hughes, 2012), Alan Hughes reports on a policy proposal of the Council of Science and Technology (CST, UK) which shared at least the starting point of smart specialization. Through this proposal, the CST's objective was to advise the Government on 'what would be the best areas to focus resources for science, technology and innovation, which could lead to applications with commercial or social benefits in around 5 years'. The proposal involved various steps to identify priority' areas, but it did not refer to any kind of self-discovery principle. I am grateful to one of the anonymous reviewers who mentioned this reference.

7. I am grateful to Dieter Ernst who mentioned to me the relevance of Hirschman's works to the analysis of RIS3 as a policy approach.

\section{References}

Aghion, P. (2012). Innovation process and policy: What do we learn from new growth theory? In J. Lerner \& S. Stern (Eds.), The rate and direction of inventive activity revisited (pp. 515-520). Chicago, IL: NBER, University of Chicago Press.

Berger, S. (2013). Making in America: From innovation to market. Cambridge: MIT Press.

Boschma, R., \& Frenken, K. (2011). Technological relatedness and regional branching. In H. Bathelt, M. P. Feldman, \& D. F. Kogler (Eds.), Beyond territory, dynamic geographies of knowledge creation, diffusion and innovation (pp. 128-155). London: Routledge.

David, P.A., \& Metcalfe, S. (2008). Only connect: Academic-business research collaboration and the formation of ecologies of innovation. Stanford Institute for Economic Policy Research, SIEPR Discussion Paper, $\mathrm{n}^{\circ} 07-33$.

Foray, D. (2015). Smart specialisation: Opportunities and challenges for regional innovation policy. London: Routledge.

Foray, D., David, P. A., \& Hall, B. (2009). Smart specialisation: The concept. In Knowledge for growth: Prospects for science, technology and innovation. Report, EUR 24047. European Union.

Foray, D., \& Frenken, K. (2016). Related variety and smart specialization, draft. Lausanne: Ecole Polytechnique Fédérale de Lausanne.

Foray, D., Mowery, D. C., \& Nelson, R. R. (2012). Public R\&D and social challenges: What lessons from mission R\&D programs. Research Policy, 41(10), 1697-1702. doi:10.1016/j.respol.2012.07.011

Hausmann, R., \& Rodrik, D. (2006). Doomed to choose: Industrial policy as predicament, draft. Blue Sky Seminar, Center for International Development, Harvard University.

Haussmann, R., \& Rodrik, D. (2003). Economic development as self-discovery. Journal of Development Economics, 72, 603-633.

Hirschman, A.O. (1967/1995). Development project observed. Washington, DC: A.Brookings Classic. 
Hirshleifer, J. (1971). The private and social value of information and the reward to inventive activity. American Economic Review, 61(4), 561-574.

Hughes, A. (2012). Choosing races and placing bets: UK national innovation policy and the globalisation of innovation systems. In D. Greenaway (Ed.), The UK in a global world (pp. 37-70). London: Center for Economic Policy Research.

McCann, P. (2015). The regional and urban policy of the European Union: Cohesion, results-orientation and smart specialisation. Cheltenham: Edward Elgar.

McCann, P., \& Ortega-Argiles, R. (2015). Smart specialization, regional growth and applications to European Union cohesion policy. Regional Studies, 49(8), 1291-1302. doi:10.1080/00343404. 2013.799769

Muscio, A., L. Rivera Leon, \& A. Reid. (2015). An empirical test of the regional innovation paradox: Can smart specialisation help overcome the regional innovation paradox? Journal of Economic Policy Reform, 18(2), 153-171. doi:10.1080/17487870.2015.1013545

Percoco, M. (2013). Strategies of regional development in European regions: Are they efficient? Cambridge Journal of Regions, Economy and Society, 6, 303-318. doi:10.1093/cjres/rst011

Rodrik, D. (2004). Industrial policy for the 21st century, UNIDO, working paper, Harvard University, reprinted as chapter 4 in: (2007) One economics, many recipes: Globalization, institutions, and economic growth. Princeton, NJ: Princeton University Press.

Rodrik, D. (2013). Green industrial policy. Working paper. School of Social Science, IAS Princeton. Sabel, C. (2004). Beyond principal-agent governance: Experimentalist organizations, learning and accountability. Amsterdam: WRR - Wetenschappelijke Raad Voor Het Regeringsbeleid.

Trajtenberg, M. (2012). Can the Nelson-arrow paradigm still be the beacon of innovation policy? In J. Lerner \& S. Stern (Eds.), The rate and direction of inventive activity revisited (pp. 679-684). Chicago: NBER, Chicago University Press.

Veugelers, R., \& Mrak, M. (2009). Catching-up member states and the knowledge economy of the European Union. In Knowledge for growth: Prospects for science, technology and innovation. Report, EUR 24047, European Union. 